\title{
IDENTIFIKASI PENYEBAB KEGAGALAN DAN APLIKASI FIBER REINFORCED COMPOSITE PADA SPLINTING
}

\author{
Putri Ovieza Maizar ${ }^{1}, K_{0 s n o}$ Suprianto ${ }^{1}$
}

${ }^{1}$ Fakultas Kedokteran Gigi Universitas Andalas

\begin{abstract}
Periodontal disease is a disease characterized by inflammation of the gingiva, loss of attachment, and damage to the alveolar bone. Bone loss caused by periodontitis may lead to tooth mobility which causes discomfort during mastication, difficulty in maintaining oral hygiene, and persistent inflammation which results in tooth loss. Splinting is a treatment to stabilize a tooth that is experiencing mobility due to periodontal problems. The most common alternative is the use of a fiber reinforced composite material that bonds to the tooth surface. Fiber works functionally, has good aesthetics, and can improve tooth stability due to mobility that occurs due to bone loss. However, in practice fiber splint also has the potential to fail due to several micro mechanisms. One of them was found in this case report. The following case report is regarding the use of a fiber reinforced composite splinting on lower anterior teeth involving two posterior teeth.
\end{abstract}

Keywords: splin, fiber reinforced composite, tooth mobility

Affiliasi penulis: ${ }^{1}$ Fakultas Kedokteran Gigi Universitas Andalas Korespondensi: Kosno Suprianto, email: skosno@yahoo.com

\section{PENDAHULUAN}

Penyakit periodontal merupakan penyakit yang ditandai dengan adanya inflamasi pada gingiva, hilangnya perlekatan, dan terdapatnya kerusakan pada tulang alveolar. Kehilangan tulang yang disebabkan oleh periodontitis dapat mengakibatkan terjadinya kegoyangan gigi yang menimbulkan ketidaknyamanan saat mastikasi, kesulitan dalam menjaga oral hygiene, dan inflamasi secara terus-menerus hingga berakibat pada kehilangan gigi. ${ }^{1,2}$ Splinting merupakan tindakan untuk menstabilkan gigi yang mengalami kegoyangan terkait masalah periodontal. Menurut The Glossary of
Prosthodontic istilah splinting didefinisikan sebagai penggabungan dua atau lebih gigi menjadi suatu unit yang rigid melalui restorasi cekat maupun lepasan atau dengan bantuan penggunaan alat. Splinting diindikasikan pada keadaan kegoyangan gigi derajat 3 dengan kerusakan tulang berat. Adapun indikasi utama penggunaan splint dalam mengontrol kegoyangan yaitu imobilisasi kegoyangan yang menyebabkan ketidaknyamanan pasien serta menstabilkan gigi pada tingkat kegoyangan yang makin bertambah. Ditambahkan oleh Strassler dan Brown splinting juga digunakan untuk mengurangi gangguan oklusal dan fungsi mastikasi. ${ }^{1,3}$ 
Dahulu splinting dilakukan dengan menggunakan bahan resin restoratif yang dipasangkan secara langsung pada kawat. Bahan ini hanya dapat berikatan secara mekanis disekitar resin restoratif namun tidak dapat berikatan secara kimiawi didalam splint. Jarak yang terbentuk antara resin komposit atau resin akrilik dan kawat berpotensi menghasilkan patahan dan tegangan yang akan membuat terjadinya kegagalan splint. Apabila splint gagal, masalah klinis yang akan terjadi berupa traumatik oklusi, gangguan periodontal, dan karies rekuren. ${ }^{4}$

Alternatif yang paling menjanjikan yakni dengan penggunaan bahan fiber reinforced composite yang berikatan pada permukaan gigi. Fiber bekerja secara fungsional, memiliki estetis yang baik, serta dapat meningkatkan stabilitas gigi akibat mobilitas yang terjadi karena kehilangan tulang. 5 Pada prakteknya, splinting dengan fiber juga berpotensi mengalami kegagalan yang disebabkan oleh beberapa mekanisme mikro diantaranya adalah perambatan retakan, terlepasnya fiber, retakan mikro pada matriks komposit, kegagalan matriks longitudinal, lepasnya ikatan fiber, dan fraktur pada fiber. Salah satunya ditemukan pada kasus yang akan dibahas. Berikut disajikan laporan kasus mengenai penggunaan splinting dengan bahan fiber reinforced composite pada gigi anterior bawah yang juga melibatkan 2 gigi posterior.

\section{KASUS}

Seorang pasien pria berusia 41 tahun datang ke rumah sakit gigi dan mulut Universitas Andalas dengan keluhan adanya karang gigi pada gigi depan bawah yang berhadapan dengan lidah sejak 10 tahun yang lalu, gusi terlihat bengkak, dan sering berdarah spontan. Selain itu pasien juga mengeluhkan terdapat beberapa gigi depan bawah yang goyang sejak 3 tahun yang lalu dan membuat pasien tidak nyaman, namun tidak diberikan perawatan apapun karena tidak terasa sakit. Pasien belum pernah membersihkan karang gigi sama sekali. Pencabutan gigi pernah dilakukan pada geraham bawah sekitar 5 tahun yang lalu, dan gigi seri bawah lepas sekitar 1 tahun yang lalu. Pasien menyikat gigi $3 x$ sehari dengan gerakan horizontal.

Berdasarkan anamnesis diketahui bahwa pasien tidak memiliki riwayat penyakit sistemik, dan sama sekali belum pernah membersihkan karang gigi. Pasien merupakan seorang pedagang makanan dan minuman di depan SD di daerah Jati sehingga pasien sibuk menjaga dagangannya saat jam sekolah selain itu pasien juga merupakan perokok berat dan bisa menghabiskan 3 
bungkus rokok dalam sehari. Pemeriksaan ekstraoral menunjukkan tidak ditemukan adanya kelainan. Pemeriksaan intraoral ditemukan adanya kalkulus supragingiva dan subgingiva menyeluruh hampir pada semua gigi, namun paling banyak pada anterior rahang bawah dan rahang atas, $\mathrm{OHI}$ dan RKP kategori buruk. Terdapat oedem disertai warna merah mengkilap pada margin gingiva bagian vestibular gigi $15,14,13,12,11,21,22,23,24,34,33$, $31,41,42$ dan pada bagian lingual/palatal gingiva gigi $13,12,11$, 21, 22, 23, 24, 33, 41, 42, dan 43. Konsistensi gingiva lunak, tanpa stippling dan permukaan licin. Resesi pada gigi 12, 11, 21, 32, 33, 41, 42, 43, 44 , dan atrisi pada gigi $11,21,32,41$, dan 42 disertai mobility grade 1 pada gigi 33 , mobility grade 2 pada gigi 32, 42, 43, 44, serta mobility grade 3 pada gigi 41 .

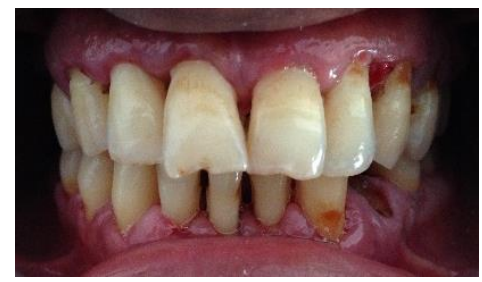

Gambar 1. Gambaran klinis pasien sebelum dilakukan splinting

Pemeriksaan radiografis menunjukkan kehilangan tulang secara horizontal pada gigi bawah terutama pada bagian anterior. Dari hasil anamnesa dan pemeriksaan didapatkan diagnosis klinis yaitu periodontitis kronis generalisata. Prognosis dikategorikan fair akibat banyaknya kehilangan tulang horizontal, kurangnya kooperasi pasien, dan kebiasaan pasien yang merupakan perokok berat. Adapun etiologi yang berperan pada kasus ini yaitu bakteri plak dan kalkulus.

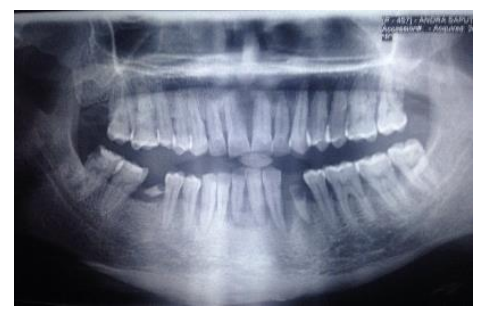

Gambar 2. Gambaran rontgen OPG

Kunjungan awal pada tanggal 28 desember 2016 dilakukan pengukuran probing depth, RKP 72,22\%, dan GI 2,49 , serta scaling dan root planing disertai DHE. Setelah kontrol 1 bulan ternyata masih terdapat mobility pada gigi 33, 32, 41, 42, 43, dan 44 sehingga pasien direncanakan untuk perawatan kuretase yang didahului oleh splinting pada gigi tersebut. Pada kunjungan pertama pengukuran probing depth disertai RKP 61\%, dan prosedur scaling dan root planing kembali dilakukan sebagai perawatan pendahuluan. Satu minggu kemudian dilakukan splinting pada gigi tersebut.

Sebelum prosedur splinting dilakukan, gigi yang akan di splint dibersihkan terlebih dahulu dengan menggunakan brush. Kemudian dilakukan pengukuran panjang fiber disepanjang gigi yang akan di splint dengan menggunakan benang. Setelah ukuran fiber didapatkan, fiber dipotong dan diletakkan diatas glass lab 
kemudian bonding dan flowable resin diaplikasikan secukupnya pada fiber dan diratakan menggunakan instrumen plastis. Daerah kerja dietsa dengan asam fosforik $37 \%$ dan didiamkan selama 30 detik kemudian dibilas dengan air serta dikeringkan. Setelah dilakukan isolasi daerah kerja dengan cotton roll, bonding diaplikasikan pada bagian lingual gigi 33, 32, 41, 42, 43, 44, 45 dan disinar selama 10 detik. Selapis tipis flowable resin diaplikasikan pada bagian lingual gigi tersebut kemudian fiber diletakkan diatasnya dan selapis tipis flowable resin kembali aplikasikan diatas fiber kemudian disinar selama 20 detik. Setelah dilakukan polishing prosedur splinting pun selesai.

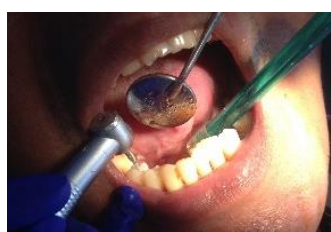

(A)

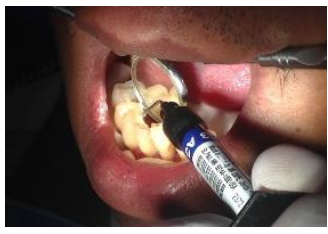

(C)

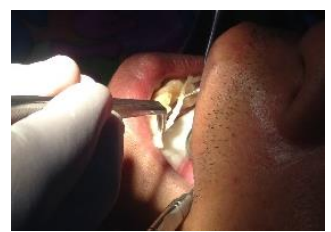

(B)

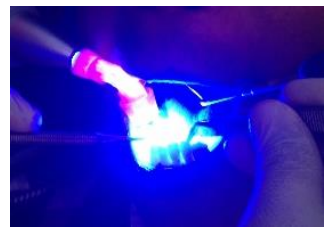

(D)
Gambar 3. A) Preparasi minimal pada oklusal gigi 44 dan 45; B) Pemasangan fiber pada lingual gigi; C) Pemberian resin komposit diatas fiber; D) Proses penyinaran menggunakan light curing unit

Pasien mengeluhkan splinting terlepas setelah mencongkel sisa makanan menggunakan tusuk gigi. Pasien datang kembali ke klinik untuk pemasangan splinting yang baru. Setelah identifikasi dilakukan maka diputuskan untuk melakukan beberapa perbaikan guna mencegah terlepasnya splinting, diantaranya dengan memaksimalkan isolasi daerah kerja, serta mengkombinasikan splinting ekstra koronal pada gigi 33, 32, 41, 42, 43 dan intra koronal pada gigi 44 dan 45 . Selain itu dilakukan penambahan flowable resin pada bagian interdental labial pada gigi tersebut serta dilakukan DHE kepada pasien untuk lebih berhati-hati dan menghindari penggunaan tusuk gigi atau alat lain yang dapat beresiko untuk terlepasnya splinting.
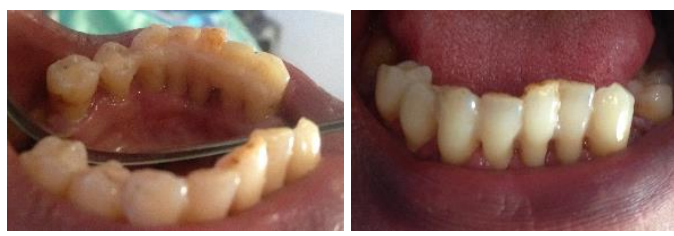

Gambar 4. Tampak lingual dan labial setelah aplikasi splinting

Kontrol dilakukan 1 minggu pasca splinting, tidak terdapat keluhan dari pasien dan splinting masih bertahan dengan baik. Pada pemeriksaan intraoral, terdapat mobility grade 1 dan gingiva berwarna merah dengan konsistensi lunak serta unstippling. Pemeriksaan klinis pada kunjungan ini memperlihatkan mobilitas gigi berkurang secara signifikan sehingga dapat dilanjutkan dengan prosedur kuretase. Kontrol berikutnya dilakukan setelah 1 bulan pasca splinting, pasien tidak memiliki keluhan dan dari hasil pemeriksaan klinis didapatkan splinting 
masih tetap bertahan dengan baik, terdapat mobilitas gigi derajat 1 pada gigi yang di splinting dan gingiva sudah tidak berwarna kemerahan lagi. Hasil pemeriksaan pada kunjungan ini menunjukkan terdapat pengurangan mobilitas gigi dari derajat 2 dan 3 menjadi derajat 1 , serta hilangnya tanda inflamasi berupa warna kemerahan pada gingiva.

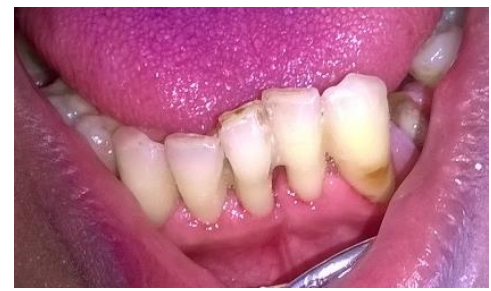

Gambar 5. Kontrol 1 bulan pasca splinting

\section{DISKUSI}

Penyakit periodontal adalah penyakit yang menyerang struktur jaringan periodontal gigi. Adanya gangguan pada struktur ini menyebabkan stabilitas gigi menjadi terganggu, yang salah satunya ditandai dengan kegoyangan gigi. Menurut Fedi dkk, kegoyangan gigi diklasifikasikan menjadi tiga derajat. Derajat 1 yaitu kegoyangan sedikit lebih besar dari normal. Derajat 2 yaitu kegoyangan sekitar $1 \mathrm{~mm}$, dan derajat 3 yaitu kegoyangan sekitar $>1 \mathrm{~mm}$ pada segala arah dan gigi dapat ditekan ke arah apikal. Pada kebanyakan kasus, insisivus mandibula merupakan gigi yang pertama kali menunjukkan tanda-tanda kegoyangan. ${ }^{1,3,6}$
Splinting diindikasikan pada gigi yang mengalami kegoyangan baik yang sifatnya tunggal maupun keseluruhan. Berdasarkan Quirynen et al.; splinting merupakan tindakan yang dapat dilakukan untuk mengatasi kegoyangan gigi, terutama gigi insisivus bawah untuk mempertahankan gigi asli pasien selama mungkin. ${ }^{1}$ Pada kasus ini splinting dilakukan pada gigi 33, 32, 41, $42,43,44$, dan 45 yang telah mengalami kehilangan tulang secara horizontal dan mengalami kegoyangan yang bervariasi mulai dari derajat 1 sampai 3 kecuali gigi 45 yang tidak mengalami kegoyangan. Perawatan splinting pada kasus ini dilakukan dengan tujuan untuk mengurangi kegoyangan sehingga gigi dapat dipertahankan selama mungkin. Adapun hasil yang didapatkan setelah pemasangan splinting pada kasus ini yaitu terjadi penurunan derajat kegoyangan gigi yang mana saat awal sebelum dilakukan perawatan gigi mengalami kegoyangan derajat 3 dan derajat 2, setelah dilakukan splinting kegoyangan berubah menjadi derajat 1 .

Metode splint yang dilakukan tidak membantu menyembuhkan struktur jaringan periodontal sehingga bila splint dilepaskan, gigi kemungkinan masih akan goyang. Splint hanya berperan sebagai terapi penunjang dalam perawatan penyakit periodontal. Dengan melakukan splinting maka akan terjadi 
distribusi gaya dari gigi yang mengalami kegoyangan ke gigi lain yang tidak goyang, dengan kata lain yakni mendapatkan dukungan dari gigi lain yang lebih sehat. Hal ini dapat memperpanjang perkiraan kehilangan gigi, memberikan stabilitas pada jaringan periodonsium disekitarnya, meningkatkan kenyamanan, fungsi, serta estetis. ${ }^{1,6}$

Penggunaan splint sebagai usaha untuk menstabilkan gigi cukup menjadi pertimbangan dalam mengurangi ketidaknyamanan pasien. Sebelum dilakukan splinting perlu dilakukan identifikasi etiologi kegoyangan gigi atau migrasi patologis yang terjadi. Bila kegoyangan gigi disebabkan oleh oklusi traumatik, maka terapi oklusal merupakan tindakan yang harus dilakukan pertama kali. Akan tetapi bila disebabkan oleh penyakit periodontal, maka inflamasi harus dikontrol sebelum memutuskan penggunaan splint. Hal ini karena inflamasi dapat menghasilkan kegoyangan pada kondisi tekanan oklusal yang normal dan dukungan periodontal normal. ${ }^{6}$ Itu sebabnya pada kasus ini sebelum splinting dilakukan, maka faktor penyebab inflamasi disingkirkan terlebih dahulu melalui tindakan scaling dan root planing. Kegoyangan gigi pada kasus ini diakibatkan oleh kehilangan tulang akibat periodontitis yang dialami pasien sehingga setelah tindakan splinting dilakukan maka dilanjutkan dengan perawatan kuretase.

Splinting biasanya dilakukan pada fase terapi inisial, dimana terapi inisial bertujuan untuk membuang semua faktor lokal yang menyebabkan peradangan gingiva serta pemberian instruksi dan motivasi pasien dalam melakukan kontrol plak. Terapi inisial juga disebut sebagai fase etiotropik karena bertujuan untuk menghilangkan faktor etiologi penyakit periodontal. Terapi inisial mencakup kontrol plak yang meliputi motivasi, edukasi dan instruksi dari pasien, scaling dan root planing, rekonturing restorasi, pembuangan karies, pemberian antimikroba serta evaluasi jaringan. Pencapaian perawatan melalui bedah periodontal dapat dilakukan bilamana terapi inisial berhasil dengan baik. ${ }^{3}$ Pada kasus ini, kondisi gigi yang di splinting mengalami pengurangan yang cukup signifikan pada kontrol 1 minggu yang menandakan terapi inisial berjalan cukup baik sehingga dapat dilanjutkan dengan prosedur kuretase.

Splint dibedakan menjadi beberapa macam tergantung bentuk, lama pemakaian, dan bahan yang digunakan. Berdasarkan bentuknya, splint dapat berupa lepasan atau cekat, yang dapat dipasang di ekstraoronal maupun intrakoronal. Berdasarkan 
lamanya pemakaian, splint dibagi menjadi splint sementara yang digunakan hanya dalam jangka waktu yang singkat (biasanya kurang dari 6 bulan), splint provisional atau semipermanen yang digunakan dalam beberapa bulan hingga beberapa tahun, dan splint permanen yang digunakan tanpa batas waktu. Berdasarkan bahan yang digunakan, splint dibagi menjadi wire-composite splint, resin splint, dan Kevlar/fiber glass splint. Wirecomposite splint meliputi kawat lentur yang diadaptasikan pada lengkung gigi dan difiksasi ke gigi dengan komposit adesif. Metode resin splint dilakukan dengan pemasangan full resin splint ke permukaan gigi. Kevlar/fiber glass splint menggunakan fiber nilon, Kevlar bands atau fiber glass yang dibasahi dalam resin dan dipasang dengan serangkaian polimerisasi ke permukaan gigi yang telah dilakukan etsa.,

Jenis splinting yang digunakan pada kasus ini merupakan fiber reinforced composite yang mana dilakukan dengan menggabungkan penggunaan bahan komposit dan polyethylene fiber. Fiber dapat meningkatkan daya kerja komposit melalui perannya sebagai stress bearing component yang dapat menahan tegangan dengan meningkatkan efek penahan beban pada matriks komposit yang sifatnya brittle. Selain itu fiber juga berperan sebagai crack-stopping sehingga dapat meningkatkan kekerasan bahan. Keunggulan penggunaan fiber reinforced composite splint adalah mudah diaplikasikan dengan preparasi gigi minimal, biaya yang dikeluarkan tergolong rendah hingga menengah bila dibandingkan dengan mahkota dan bridge, reversibel; mudah dilepas ketika tidak lagi diperlukan, mudah diperbaiki apabila terdapat kesalahan, mendukung perawatan yang lebih agresif yang dilakukan pada gigi geligi dengan prognosis yang diragukan berdasarkan stabilisasi jangka panjang, dan memiliki nilai estetik yang baik. Adapun kekurangan penggunaan fiber reinforced composite splint yakni saat diberikan gaya secara longitudinal, struktur fiber reinforced composite akan mengalami mekanisme mikro yang berujung pada kegagalan. Mekanisme mikro tersebut diantaranya adalah perambatan retakan, terlepasnya fiber, retakan mikro pada matriks komposit, kegagalan matriks longitudinal, lepasnya ikatan fiber, dan fraktur pada fiber. Semua mekanisme kegagalan diatas tergantung pada arah beban yang diberikan pada splint. Retakan terkecil sekalipun apabila terjadi pada posisi strategis akan menyebabkan terjadinya perambatan tegangan dan berakibat pada kegagalan splint. ${ }^{7,8,9}$ 
Pada kasus ini splinting dilakukan dua kali karena splinting terlepas 2 hari setelah pemasangan splinting pertama. Berdasarkan keterangan pasien splinting terlepas setelah pasien mencongkel sisa makanan dengan tusuk gigi pada selasela gigi yang dilakukan splinting. Lepasnya splinting pada kasus ini sesuai dengan mekanisme mikro yang mengakibatkan terjadinya kegagalan splinting seperti yang telah disebutkan diatas. Hal ini berkaitan gaya konstan yang diberikan pasien pada interdental gigi yang di splint melalui tusuk gigi saat melakukan gerakan mencongkel sehingga mengakibatkan timbulnya retakan mikro pada matriks komposit yang membuat splinting terlepas dari gigi.

Selain gaya yang ditimbulkan pasien melalui gerakan mencongkel, faktor lain yang berperan dalam lepasnya splinting pada kasus ini diduga akibat isolasi pada daerah kerja yang kurang efektif. Saliva, darah, dan kontaminasi lainnya setelah dilakukan etsa dianggap sebagai penyebab utama dari kegagalan pada bonding resin komposit. Metode yang umum digunakan untuk mengontrol cairan diantaranya dengan penggunaan rubber dam, cotton roll, dan dikombinasikan dengan saliva ejector. Rubber dam akan memberikan daerah operatif yang kering dan ideal selama prosedur tindakan.
Oleh sebab itu isolasi daerah kerja dengan menggunakan rubber dam disarankan untuk mengurangi kegagalan pada ikatan resin komposit dan gigi sehingga dapat memperkecil kemungkinan terlepasnya splinting. Namun berdasarkan studi klinis selama lebih dari 10 terhadap penggunaan material isolasi daerah kerja dengan resin komposit menunjukkan tidak terdapatnya perbedaan yang signifikan antara penggunaan rubber dam dengan kombinasi penggunaan cotton roll dan aspirasi dengan saliva ejector asalkan penggunaan cotton roll dan aspirasi saliva ejector dilakukan secara efektif. ${ }^{11}$

Faktor penyebab kegagalan splinting lainnya pada kasus ini yakni akibat penempatan fiber yang kurang tepat pada kunjungan pertama. Fiber ditempatkan secara ekstra koronal yaitu pada bagian lingual gigi padahal splinting yang dilakukan tidak hanya meliputi gigi anterior (gigi 33, 32, 41, 42, 43) tetapi juga melibatkan gigi posterior (gigi 44 dan 45). Penggunaan splint secara intra koronal diperlukan terutama pada gigi posterior dengan tujuan untuk meningkatkan stabilisasi, mencegah terjadinya traumatik oklusi, serta untuk mendapatkan estetik yang baik. ${ }^{10}$ Oleh sebab itu pada kunjungan selanjutnya, splinting kembali dilakukan namun dengan melakukan kombinasi penempatan fiber yaitu secara ekstra 
koronal pada gigi 33, 32, 41, 42, 43 dan intra koronal pada gigi 44 dan 45 .

Faktor lain yang diduga berkontribusi pada kegagalan splinting pertama yakni tidak dilakukannya perluasan resin adesif dan komposit hingga bagian interproksimal. Pada splinting pertama bahan resin adesif dan komposit hanya diberikan terbatas pada bagian lingualnya saja tanpa melibatkan bagian interproksimal fasial. Padahal pemberian etsa, resin adesif, dan komposit seharusnya diberikan tidak hanya pada bagian lingual tetapi diperluas hingga interproksimal fasial agar didapatkan kontak yang baik serta meningkatkan kekuatan ikatan splint. Namun yang harus diperhatikan adalah sisa resin harus dibersihkan dan tidak sampai menutupi embrasur gingiva. ${ }^{9}$

Faktor terakhir yang berperan pada kegagalan splinting pada pemasangan pertama yakni kurangnya edukasi kepada pasien mengenai keterbatasan penggunaan splint. Menjaga oral hygiene akan sulit dilakukan pada pasien yang melakukan perawatan splinting sehingga hal ini perlu diberikan perhatian khusus agar keberhasilan splinting dapat dicapai dalam jangka waktu lama. Hasil studi menunjukkan bahwa kombinasi penggunaan sikat gigi konvensional dan sikat interdental terbukti lebih efektif menghilangkan biofilm dan inflamasi gingiva pasien dengan splint dibandingkan dengan penggunaan sikat gigi konvensional saja ataupun dengan kombinasi dental floss. ${ }^{2}$ Oleh sebab itu edukasi kepada pasien mengenai penjagaan oral hygiene dengan menggunakan kombinasi sikat gigi dan sikat interdental perlu dilakukan sehingga penggunaan bahan lain seperti tusuk gigi yang berpotensi melepas splint dari permukaan gigi dapat dihindari.

\section{SIMPULAN}

Splinting merupakan perawatan yang dapat dilakukan untuk menstabilkan gigi yang mengalami kegoyangan akibat masalah periodontal. Pemilihan jenis splinting dapat dilakukan dengan berbagai pertimbangan dan penggunaan fiber reinforced composite merupakan salah satu alternatif bahan dalam splinting dengan berbagai keunggulan. Namun hal-hal yang berpotensi menyebabkan terlepasnya splinting juga perlu diperhatikan agar dapat dihindari dan keberhasilan splinting dapat tercapai.

\section{KEPUSTAKAAN}

1. Lawande SA \& Lawande GS. Management of Periodontally Involved Anterior Teeth by Glass

Fiber Reinforced Composite Splinting: A Clinical Report with 5- 
Year Recall. Saudi J. Oral. Dent. 2016; 1(2):74-79

2. Pereira et al. - Stabilizing periodontally compromised teeth with glass fiber-reinforced composite resin - case report. RSBO. 2016 Jul-Sep;13(3):217-21

3. Lilies SA. Alternatif Splinting Pada Kegoyangan Gigi Akibat Penyakit Periodontal. As-Syifaa. 2015; 07 (02):209-218

4. Moazzami SM, Zakeri M, Arjmand $\mathrm{N}$ and Koohestanian N. A Novel FRC Splint of Periodontally Treated Anterior Mandibular Teeth using Translucent Rigid Special Tray Technique (A Case Report). Austin Dent Sci. 2016; 1(1): 1001

5. Pereira et al. - Stabilizing periodontally compromised teeth with glass fiber-reinforced composite resin - case report. RSBO. 2016 Jul-Sep;13(3):217-21

6. Arni ID. Berbagai jenis splint untuk mengurangi kegoyangan gigi. Dentofasial. 2011; 10(2):124-127

7. Mittal, S. Tooth Splinting: An Update. Heal Talk. 2013; 5(3): 3839.

8. Ambarawati, IGAD. Laporan Kasus: Penatalaksanaan Mobilitas Gigi dengan Splinting Fiber Komposit. Univeritas Udayana. Hal: 7-8.

9. Vineet K, Sanjiv MP, Rasika J. Bonded Reinforcing Materials For
Esthetic Anterior Periodontal Tooth Stabilization: A Case Report. International Journal of Dental Clinics 2011:3(1): 90-91

10. Mora O, Yuniarti S, Yulianti K, Airina. Adjuntive Intracoronal Splintt in Periodontal Treatment: Report of Two Cases. Journal of Dentistry Indonesia 2014; 21(3): 9499

11. A. Raskin · J. C. Setcos · J. Vreven • N.H.F. Wilson. Influence of the isolation method on the 10-year clinical behaviour of posterior resin composite restorations. Clin Oral Invest (2000) 4:148-152. 